\title{
$\begin{array}{llllllll}V & 0 & \mathbf{r} & \mathbf{w} & \mathbf{0} & \mathbf{r} & \mathrm{t} .\end{array}$
}

Gewifs ist es ein sehr gewagtes Unternehmen, mit einer deutschen Bearbeitung von Cuvier's Régne animal hervorzutreten, da diefs Meisterwerk (wie auch die beiden deutschen Uebersetzungen desselben, welche uns Schinz und Voigt geliefert haben) einerseits z. Th. veraltet ist, andererseits eine genaue Kenntnifs der Thiere von Seiten des Bearbeiters verlangt. Am meisten aber wird es gewagt erscheinen, wenn ein junger Mann, wie der Herausgeber, ohne alle Unterstützung, ganz und gar auf seine eigenen Kräfte beschränkt, sich einer solchen Arbeit unterzieht. Es wird daher hier am Orte sein, wenn zur Entschuldigung eines derartigen Unternehmens einige Worte vorangeschickt werden.

Obgleich die Zahl der kleineren IIand- und Lehrbücher und Grundrisse der Zoologie alljährlich bedeutend zunimmt und auch wohl hin und wieder ein Ilandbuch von etwas gröfserem Umfange erscheint: so fehlt es doch bei uns gänzlich an einem ausführlicheren wahrhaft wissenschaftlich abgefafsten Compendium. Dieser Mangel hat sich besonders Lehrern an wissenschaftlichen Sekundär- und an höheren Bürgerschulen fühlbar gemacht, vorzugsweise aber solchen Lehrern der Naturgeschichte, welche während ihrer Universitätsstudien nicht hinreichende Gelegenheit gehabt 
haben, sich einem speziellen Studium der Nalurgeschichte hinzugeben und denen es daher auch - da nirgend Vorlesungen über Encyclopädic der Naturwissenschaften gehalten werden -- an einer Anleitung gefechlt hat, diese Wissenschaften von einer streng wissenschaftichen Seite aufzufassen.

Die Absicht des Ilerausgebers war nun, diesem dringend gefühlten Bedürfnisse abzuhelfen. Es schien ihm aber nicht angemessen ein ganz neues Werk zu diesem Zwecke zu verfassen, zumal da er in Cuvier's Règne animal, dessen Galtungen er 1837 in den Sälen des Königl. zoologischen Huseums zu Berlin - so weit das Material dazu in dieser Sammlung ihm zur Benuzzung offen stand - zu revidiren begonnen hatte, ein treffliches Auskunftsmittel erblickte. Dieses grofsartige Buch bedurfte jedoch bedeutender Umgestaltungen: es war schon 1817 geschrieben - die \%weite Auflage, v. J. 1829, hat keine sehr wesentlichen Veränderungen erlitten -, zunächst nur für Frankreich eingerichtet und als selbstständiges Buch ausgegeben, obgleich die Leçons d'anatomie comparée, die Recherclies sur les ossements fossiles und die IIs/. des progrès des sciences naturelles sich demselben anschliefsen. Diese voluminösen Werke konnten eben wegen ihrer Ausdehnung der Uebersetzung des Kígne animal nicht einverleibt werden; auch hätlen sie gleichfalls wesentliche Abänderungen erfahren müssen um dem beabsichtigten Zwecke zu genügen. Der Herausgeber hat es daher vorgezogen, den allgemeinen Theil des Rigne animal durch Nachträge zu jedem Kapitel bedculend zu erweitern und dafür den entomologischen $\Lambda$ bschnilt des speziellen Theiles abzukürzen, wofür sich auch höchst be . deutende Autoritäten ausgesprochen haben. Ilieraus geht unzweifelhaft hervor, dafs nur der allgemeine Theil wegen seiner Ergänzungen zu einem, in Verhältnisse zum Originale so bedeutenden. ['mfange angewaclisen isl: der spezielle Theil hingegen wird ungenchtet der viellacheren Bereicherungen. die dureh die Fortschrilte der Wissenschaft nöthig geworden sind. und der $\Lambda$ ufführung 
sämmtlicher deutschen Wirbelihiere u. s. w. dennoch cine derartige Ausdehnung sicher nicht erfahren. Alle Stellen, welche sich nicht im Originale befinden, sind in [ ] geschlossen.

An Aufmunterungen zu einer solchen Arbeit hat es dem Uebersetzer nicht gefehlt und 1840 gestallete ihm sogar des Herrn Alexander v. Humboldt Excellenz, wie auch 1843 IIerr Professor Ehrenberg Densulben seine Bearbeitung des Cuvier'schen Werkes widmen zu dürfen. So wurde am fünfundsiebenzigjährigen Geburtstage G. Cuvier's (25. Aug. 1844) der Druck begonnen.

Dafs der vorliegende erste Band nicht überall gleich ausführlich ist, liegt in der Natur der Sache: der Herausgeber wollte besonders das hervorheben, was den bei ilren Privatstudien sich selbst überlassenen Lehrern an Schulen fast ganz entgeht, während er das Uebrige gedrängter geien konnte. Ebenso liefs es sich nicht vermeiden, dals nicht Alles gleich übersichtlich dargestellt wurde: diefs lag theils in der Anordnung der Kapitel im Originale, theils daran, dafs während des Drukkes noch einige Aenderungen und Zusälze nöthig geworden waren. Wer weitere Belchrung verlangt, als ihm der vorliegende Leilfaden zu geben im Stande ist, findet an den gehörigen Orlen eine kurze Uebersicht der vichtigeren Litteratur: ich werde mich sehr glücklich schätzen, wenn ich den Anfänger oder weniger Geübten zu den Werken eines Ilumboldt, Ehrenberg; J. Müller, R. Wagner, Krause und anderer Koryphäen der Naturwissenschaften und vielleicht auch zugleich zu einer nicht ganz gedankenlosen unmittelbaren Naturanschauung geführt haben werde; denn für Meister oder auch nur geübte Forscher zu schreiben habe ich nie beabsichtigt, obgleich ich zu hoffen wage, dafs der spezielle Theil (welcher bald erscheinen wird und wie ich wiederholentlich versichere, wegen der präcisen Schreibart und des äulserst kompressen Satzes den ersten Band an Stärke keinesweges übertreffen soll) auch geübteren Zoologen manche Bequemlichkeit darbielen werde. 
Einige Personen haben mich bei dieser Arbeit kräftig unterstülzt und mich dadurch aufs Innigste verpflichtet. Es ist mir leider nur gestattet, den Ilerrn Dr. Kunstmann, Sekretär der hiesigen Königlichen Bibliothek namhaft zu machen: derselbe ist mir stets mit gröfster Gefälligkeit entgegengekommen, wodurch für mich einigermafsen die Beschränkung in der Benutzung des genannlen Institutes ausgeglichen worden ist; auch hat früher Herr Kustos Dr. Pinder durch seine unbegrenzte Liberalität mein Unternehmen sehr gevördert. Den Genannten und Ungenannten sage ich hiermit meinen herzlichsten Dank!

So übergebe ich nun dem betreffenden Publikum den vorliegenden, ersten, Theil meiner Bearbeitung des Règne animal, vor deren Benutzung man gewogentlichst die hinten angezeigten Druckfehler verbessern wolle, mit der Bitte um gütige Nachsicht und mit dem innigen Wunsche, dafs das Werk auch in dieser neuen Gestalt Nutzen stiften, namentlich vielen Lehrern ihre schweren Amtspflichten in etwas erleichtern und auch Manchem, der im Umgange mit der erhabenen Natur für das Bittere, was das Leben nur zu oft darreicht, Entschädigung sucht, zum Prieslerthume dieser Gottheit verhelfen möge!

Berlin, den 20. Juni 1846.

\section{Der Ueberselzer.}

